BMJ Open

Diabetes

Research

\& Care

\section{'Never again will I be carefree': a qualitative study of the impact of hypoglycemia on quality of life among adults with type 1 diabetes}

To cite: Chatwin $\mathrm{H}$, Broadley $\mathrm{M}$, Valdersdorf Jensen M, et al. 'Never again will I be carefree': a qualitative study of the impact of hypoglycemia on quality of life among adults with type 1 diabetes. BMJ Open Diab Res Care 2021;9:e002322. doi:10.1136/ bmjdrc-2021-002322

- Supplemental material is published online only. To view, please visit the journal online (http://dx.doi.org/10.1136/ bmjdrc-2021-002322).

Received 9 April 2021 Accepted 17 July 2021

Check for updates

(c) Author(s) (or their employer(s)) 2021. Re-use permitted under CC BY-NC. No commercial re-use. See rights and permissions. Published by BMJ.

For numbered affiliations see end of article.

Correspondence to Ms Hannah Chatwin; hchatwin@health.sdu.dk

\section{ABSTRACT}

Introduction Achieving glycemic targets and optimizing quality of life (QoL) are important goals of type 1 diabetes care. Hypoglycemia is a common barrier to achieving targets and can be associated with significant distress. However, the impact of hypoglycemia on QoL is not fully understood. The aim of this study was to explore how adults with type 1 diabetes are impacted by hypoglycemia in areas of life that are important to their overall QoL. Research design and methods Participants responded to a web-based qualitative survey involving a novel 'Wheel of Life' activity. Responses were analyzed using reflexive thematic analysis.

Results The final sample included 219 adults with type 1 diabetes from Denmark, Germany, the Netherlands, and the UK. They had a mean \pm SD age of $39 \pm 13$ years and diabetes duration of $20 \pm 14$ years. Participants identified eight areas of life important to their overall QoL, including relationships and social life, work and studies, leisure and physical activity, everyday life, sleep, sex life, physical health, and mental health. Participants reported emotional, behavioral, cognitive, and social impacts of hypoglycemia within domains. Across domains, participants described interruptions, limited participation in activities, exhaustion, fear of hypoglycemia, compensatory strategies to prevent hypoglycemia, and reduced spontaneity.

Conclusions The findings emphasize the profound impact of hypoglycemia on QoL and diabetes self-care behaviors. Diabetes services should be aware of and address the burden of hypoglycemia to provide person-centered care. Clinicians could ask individuals how hypoglycemia affects important areas of their lives to better understand the personal impact and develop tailored management plans.

\section{INTRODUCTION}

Hypoglycemia remains a common barrier to optimal glycemic management for adults with type 1 diabetes, despite advances in insulin analogs, insulin delivery devices, and glucose monitoring devices. ${ }^{1}{ }^{2}$ Episodes can be frightening and life-threatening, with some resulting in loss of consciousness, seizure,

\section{Significance of this study}

What is already known about this subject?

- Hypoglycemia is common and burdensome among adults with type 1 diabetes, yet its impact on quality of life $(\mathrm{Q} o \mathrm{~L})$ is not fully understood.

What are the new findings?

- Adults with type 1 diabetes experience emotional, social, cognitive, and behavioral impacts of hypoglycemia on their relationships, work/studies, leisure, everyday life, sleep, sex life, and physical/mental health.

- There are short-term impacts of hypoglycemic episodes as well as persistent impacts of living with the risk of hypoglycemia.

- Hypoglycemic episodes caused interruptions, limited participation in activities, reduced performance on activities/tasks, exhaustion, and concentration difficulties.

- In terms of living with the risk of hypoglycemia, participants feared and were preoccupied with hypoglycemia, maintained higher glucose and frequently checked their glucose to prevent hypoglycemia, and were limited in their spontaneity.

How might these results change the focus of research or clinical practice?

- Healthcare professionals' need to understand the multifaceted impact of hypoglycemia on QoL and diabetes self-management.

- Clinicians could ask individuals how hypoglycemia affects important areas of their lives to better understand the personal impact, then facilitate access to tools and develop tailored hypoglycemia management plans accordingly.

- Further research is needed to determine whether these results are corroborated in unselected and culturally diverse samples.

and rarely, sudden death. ${ }^{3}$ Adults with type 1 diabetes report that hypoglycemia impairs their sleep quality, work productivity, driving safety, and overall quality of life (QoL). ${ }^{4}$ 
QoL is increasingly emphasized as an important health outcome, with optimization of QoL a fundamental goal of diabetes care. ${ }^{6}$ It is a subjective and multi-faceted construct encompassing physical, psychological, and social factors. ${ }^{7}$ While the impact of hypoglycemia on QoL is recognized in research and clinical practice, it is not well understood. ${ }^{7}$

Previous studies of the impact of hypoglycemia have focused almost exclusively on psychological outcomes, namely fear of hypoglycemia. ${ }^{8}$ This restricts our understanding of the burden to the impact on emotional aspects of QoL and limits our understanding of other potentially important domains (eg, work or relationships). In addition, past research has used measures that assess other constructs (eg, health status) and applied fixed frameworks of QoL that may not be relevant to study participants. ${ }^{9}$

While qualitative studies have focused on experiences of impaired hypoglycemia awareness and the challenges imposed by hypoglycemia, ${ }^{2}{ }^{10}$ no study has investigated how adults with type 1 diabetes are affected by hypoglycemia in QoL domains that are personally important to them. The aim of this study was to explore the impact of hypoglycemia on QoL by inviting adults with type 1 diabetes to describe how important areas of their lives are affected by hypoglycemia. This study was conducted across four European countries (Denmark, Germany, the Netherlands, and the UK), with the secondary aim of examining between-country differences in hypoglycemia impacts.

\section{RESEARCH DESIGN AND METHODS}

This study involved a web-based qualitative survey.

\section{Participants}

In each of the target countries, the study was advertised in diabetes clinics, on social media, and via e-newsletters distributed by diabetes associations. Individuals were eligible to participate if they were: $\geq 18$ years old, selfreporting a diagnosis of type 1 diabetes, and living in one of the target countries. Sample size targets were N=50 in each country, based on previous studies of people with diabetes achieving conceptual saturation with similar sample sizes. ${ }^{11}$

\section{Materials}

The survey involved a 'Wheel of Life' activity that asked participants to identify areas of life that are important to their overall QoL, then describe how hypoglycemia affects those areas they identified (see figure 1). This activity has been implemented as an interview method in past research on the impact of diabetes on QoL. ${ }^{12} 13$ The method was adapted to include written instructions that enabled participants to complete the activity online without interviewer facilitation.

Demographic and clinical characteristics were assessed using validated measures and study-specific items. Eight items of the Hypoglycaemia Awareness Questionnaire ${ }^{14}$ assessed self-reported frequency, severity, and awareness of hypoglycemia in the past 12 months. The single-item Gold Score ${ }^{15}$ assessed self-reported hypoglycemia awareness. The six-item Worry subscale of the Hypoglycemia Fear Survey Short Form ${ }^{16}$ assessed fear of hypoglycemia. Since the study was conducted during the COVID-19 pandemic, a nine-item adaptation of the Diabetes Attitudes, Wishes, and Needs 2 Impact of Diabetes Profile (DIDP) ${ }^{17}$ was included to assess the impact of the pandemic on diabetes and various aspects of QoL. Five adults with type 1 diabetes piloted the survey to verify the readability, relevance, and importance of survey questions. English survey content was then translated into Danish, Dutch, and German in accordance with best practice guidelines. ${ }^{18}$

\section{Data collection}

The survey was hosted on REDCap, ${ }^{19}$ an online survey platform accessible via computer, tablet, or smartphone. Participants responded to screening questions to determine their eligibility. Eligible participants then reviewed an Information Sheet and gave their consent to participate anonymously by selecting checkboxes. Purposive sampling was used to recruit equal numbers of participants in each country and participants reporting the presence or absence of severe hypoglycemia in the past year. Once sample size targets were met for each group, data were checked for completeness and the survey was closed.

\section{Data analysis}

Survey records were imported into SPSS V.22 and NVivo V.12. Non-English records were translated via Google Translate then reviewed by native speakers of the original language for semantic equivalence between original and translated versions. Translated free-text responses were analyzed using reflexive thematic analysis. Two researchers (HC and MVJ) developed the coding framework with consultation from coauthors. HC coded 100\% of the dataset and MVJ coded 20\% for comparison. Researchers generated initial codes by familiarizing themselves with free-text responses then summarizing data extracts line-by-line within QoL domains. Extracts were only coded if they were meaningful and able to be interpreted, usually more than one word or short responses. Codes were observed to be qualitatively similar between countries; therefore, responses were pooled for theme development. Semantically related codes were clustered to develop themes within QoL domains. Themes were reviewed for goodness-of-fit, coherence, and discrimination from other themes. Researchers determined whether extracts within domains reflected emotional, behavioral, cognitive, or social impacts to evaluate the impact of hypoglycemia across these areas of functioning. Descriptive statistics were calculated for demographic and clinical variables. Between-group differences (by gender, country, and experience of severe hypoglycemia in the past year) were examined using $\chi^{2}$ tests. 
The next few questions are about hypoglycaemia and your quality of life. We would like you to imagine this wheel as a representation of your quality of life. This wheel is divided into sections. Each section represents an area of life that is important to the quality of your life right now.

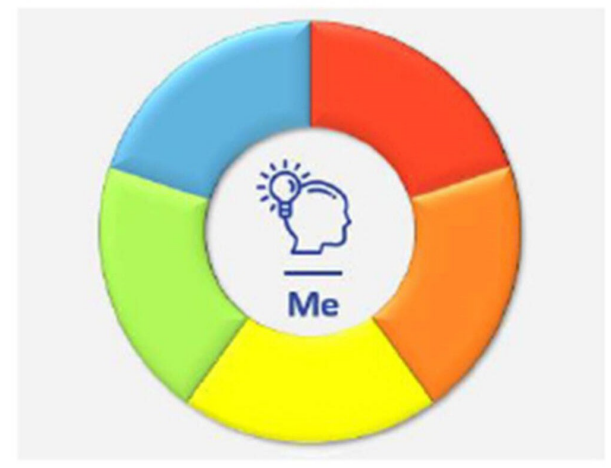

What is important to you may not be the same as what is important to someone else. That is OK. There are no right or wrong answers. Here are some examples:

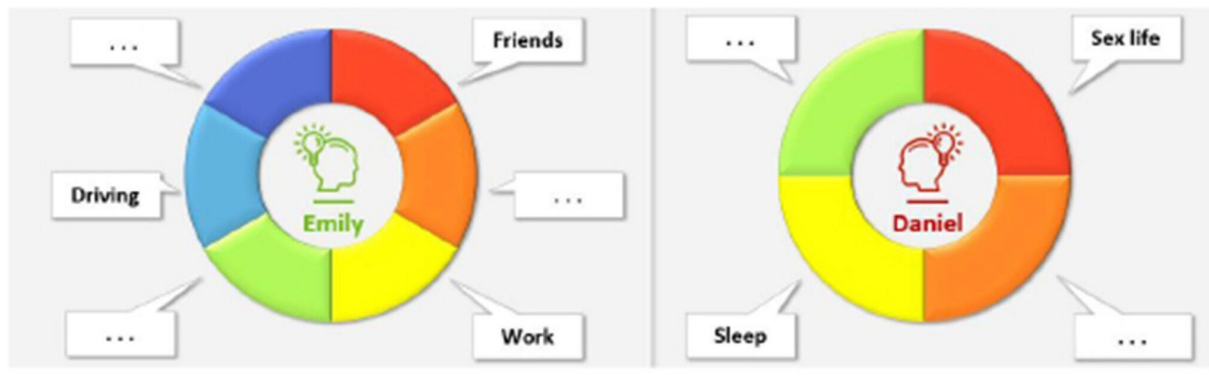

To complete this part of the survey, please think about areas of your life that are important to you. In the first box below, type a short label for an area of life that is important to you. In the second box, tell us (in as much detail as possible) about how hypoglycaemia affects that area of your life.

All types of hypoglycaemia are relevant (e.g., daytime, night-time, self-treated, or those where you need help from another person). Sometimes, an area of life may be affected not just by having a hypo but also by your worries about having a hypo or the efforts you make to avoid/treat hypos. Most people can think of at least five areas of life that are important to them.

Figure 1 Instructions for the 'Wheel of Life' activity.

\section{RESULTS}

Of the 237 survey respondents, 18 did not attempt the 'Wheel of Life' and were excluded. Excluded participants were more likely to be men, engaged in unpaid work, and report more worry about hypoglycemia, compared to included participants (online supplemental table 1).

\section{Sample characteristics}

The final sample included 219 adults with type 1 diabetes. They had a mean \pm SD age of $39 \pm 13$ years and diabetes duration of $20 \pm 14$ years. Eighty-three per cent $(n=182)$ were women. Sixty-nine per cent $(n=151)$ were living with a spouse or partner. Forty-two per cent $(n=92)$ were working full-time. Seventy-seven per cent $(\mathrm{n}=170)$ were using flash glucose monitoring or continuous glucose monitoring (CGM). Fifty-three per cent
( $\mathrm{n}=116)$ were using an insulin pump. Forty-seven per cent $(n=102)$ were using multiple daily injections. Participants reported a median (IQR) of 4 (2-6) hypoglycemic episodes of any severity in the past week. Thirty-two per cent $(n=70)$ of the sample reported at least one severe episode in the past year. Frequency of severe hypoglycemia in the past year ranged from 1 to 240 episodes per person, with a total of 624 episodes across those 70 participants reporting at least one episode. Thirty-nine per cent $(n=87)$ reported impaired awareness of hypoglycemia (IAH) (Gold Score $\geq 4) .{ }^{15}$ Fifty-one per cent $(n=123)$ reported a comorbid physical or mental health diagnosis. Mean composite scores on the adapted DIDP indicated that overall QoL had been 'slightly negatively' impacted by the COVID-19 pandemic (online supplemental table 2). 
Table 1 QoL domains important to overall QoL among adults with type 1 diabetes

\begin{tabular}{|c|c|c|}
\hline QoL domain & Number of references* & Description \\
\hline Relationships and social life & 233 & $\begin{array}{l}\text { Relationships with spouses/partners, children, other family } \\
\text { members, and friends }\end{array}$ \\
\hline Work and studies & 176 & Work, school/university, and other vocational activities \\
\hline Leisure and physical activity & 175 & Sports, exercise, travel/vacation, and other hobbies \\
\hline Everyday life & 137 & Driving, eating, household duties, and other functional activities \\
\hline Sleep & 80 & Bedtime routine, sleep, and next-day functioning \\
\hline Sex life & 34 & Sexual activity and intimacy \\
\hline Physical health & 24 & Specific aspects of health (eg, pregnancy) \\
\hline Mental health & 10 & Mood fluctuations and emotional difficulties \\
\hline
\end{tabular}

*Domains may have been nominated multiple times across the 'Wheel of Life' by a single participant (eg, 'work meetings', 'working life', and 'talks with colleagues'), hence the number of references for a QoL domain may exceed the total number of participants.

QoL, quality of life.

\section{QoL domains}

Using the 'Wheel of Life', participants identified a mean \pm SD of $4 \pm 1$ areas of life important to their overall QoL. Table 1 presents the eight QoL domains identified across responses, including the number of times each domain was nominated. Women were more likely than men to nominate relationships as an important area of life. There were no further differences in the number of times each domain was nominated by gender, country, or experience of severe hypoglycemia in the past year (online supplemental tables 3-5).

\section{Impact of hypoglycemia on QoL}

Table 2 presents the reported impact of hypoglycemia on QoL domains. The length of free-text responses ranged from 1 to 382 words, with a median of 24 words. Of the 859 responses, $74 \%$ ( $\mathrm{n}=635)$ were meaningful and able to be interpreted. In five of the eight domains, participants indicated that every area of functioning was affected by hypoglycemia. Participants rarely reported that QoL domains were unaffected by hypoglycemia $(5 \% ; n=29$ of meaningful responses).

Participants from Germany were more likely than participants from other countries to report an impact on their leisure and physical activity. Participants from the Netherlands were more likely to report mental health impacts. Women were more likely than men to report an impact on their work or studies. Participants who experienced severe hypoglycemia in the past year were more likely than participants who had not experienced severe hypoglycemia in the past year to report an impact on their sex life. There were no further differences between groups (online supplemental tables 6-8). Box 1 presents participants' quotations to illustrate themes.

\section{Relationships and social life}

\section{Disrupted quality time}

Participants explained that hypoglycemia and its aftereffects limited their ability to interact with family and friends. During hypoglycemia, they found it difficult to speak, respond, and 'connect emotionally with what people are saying'. Some felt embarrassed about their 'childish', 'resistant', or drunken-like behavior during hypoglycemia. They cancelled plans or interrupted activities to treat hypoglycemia, which was annoying for them and meant that others had to wait for them. Some were unable to enjoy meals with friends due to having eaten to treat hypoglycemia before the meal. Participants felt 'drained' following hypoglycemia and lacked energy for interaction. They felt moody and irritable, which sometimes resulted in arguments or 'being unfairly angry' towards their children. Some explained that their partners became frustrated with them for recurrences. Participants were worried about burdening others, particularly family members who helped with treatment or were inconvenienced by interruptions (eg, sensor alarms), so hypoglycemic events were 'downplayed' or treated discreetly to avoid worrying or bothering others.

\section{Reduced ability to parent}

Some participants found it difficult to take care of their children during hypoglycemia, as they had to 'attend to their own needs first'. They felt unable to fulfill their usual role and responsibilities due to hypoglycemia, and sometimes had to relinquish care of their children to their spouse/partner. Some stated that their children had 'treated hypos for them' and 'taken care of them', which was distressing for parents. Some expressed concerns about taking care of their child without another adult present, due to the risk of hypoglycemia.

\section{Fears and compensatory strategies}

Participants feared hypoglycemia occurring in the company of others and felt uncomfortable with others potentially witnessing episodes. Consequently, they accepted less social invitations, participated less actively in certain activities, and maintained higher glucose levels for social events. Some felt 'trapped', 'paralyzed', and completely unable to participate in social events due to the risk of hypoglycemia. They reported a lack 
Table 2 Impact of hypoglycemia on QoL domains: themes, number of references $(\mathrm{N})$, described impacts, and areas of functioning affected

\begin{tabular}{|c|c|c|c|c|c|}
\hline Domains/Themes & $\mathbf{N}$ & Emotional & Behavioral & Cognitive & Social \\
\hline Relationships and social life & 141 & $\mathrm{x}$ & $\mathrm{X}$ & $\mathrm{X}$ & $\mathrm{X}$ \\
\hline Disrupted quality time & 117 & \multicolumn{4}{|c|}{$\begin{array}{l}\text { Interrupted/cancelled activities, irritability/conflict, worry about burdening others, fatigue, } \\
\text { unable to interact with others }\end{array}$} \\
\hline Reduced ability to parent & 27 & \multicolumn{4}{|c|}{ Unable to fulfil roles and responsibilites, unable to take care of children } \\
\hline Fears and compensatory strategies & 25 & \multicolumn{4}{|c|}{ Lack spontaneity, less active participation, maintain higher glucose levels } \\
\hline Work and studies & 148 & $\mathrm{X}$ & $\mathrm{X}$ & $\mathrm{X}$ & $\mathrm{X}$ \\
\hline Reduced productivity or performance & 105 & \multicolumn{4}{|c|}{$\begin{array}{l}\text { Fatigue, poor concentration, interrupted/stopped tasks, fear negative evaluation from } \\
\text { colleagues, late arrival/sick leave }\end{array}$} \\
\hline Fears and compensatory strategies & 43 & \multicolumn{4}{|c|}{ Fear of hypoglycemia, maintain higher glucose levels, check glucose levels frequently } \\
\hline Limited employment prospects & 10 & \multicolumn{4}{|c|}{$\begin{array}{l}\text { Difficult to get/keep job, work part-time for less pressure, unable to pursue certain job } \\
\text { prospects }\end{array}$} \\
\hline Leisure and physical activity & 122 & $\mathrm{x}$ & $\mathrm{x}$ & $\mathrm{x}$ & $\mathrm{X}$ \\
\hline Fears and limited spontaneity & 71 & \multicolumn{4}{|c|}{$\begin{array}{l}\text { Limited/ceased participation, lack spontaneity, fear of hypoglycemia, maintain higher glucose } \\
\text { levels, check glucose levels repeatedly }\end{array}$} \\
\hline Interrupted, discontinued, or cancelled activities & 61 & \multicolumn{4}{|c|}{$\begin{array}{l}\text { Breaks taken, activities cut short/cancelled, reduced performance, fatigue, concentration } \\
\text { difficulties }\end{array}$} \\
\hline Everyday life & 89 & $\mathrm{X}$ & $\mathrm{x}$ & $\mathrm{x}$ & $x$ \\
\hline Limited driving freedom & 47 & \multicolumn{4}{|c|}{$\begin{array}{l}\text { Fear of hypoglycemia, maintain higher glucose levels, check glucose levels frequently, unable } \\
\text { to drive/delayed in starting trip }\end{array}$} \\
\hline Day-to-day burdens & 30 & \multicolumn{4}{|c|}{$\begin{array}{l}\text { Carry treatments/equipment, interrupted/discontinued household duties, financial burden of } \\
\text { treatments }\end{array}$} \\
\hline Limited dietary freedom & 12 & \multicolumn{4}{|c|}{ Food choices dictated by glucose levels, unable to enjoy foods associated with hypoglycemia } \\
\hline Sleep & 62 & $\mathrm{x}$ & $\mathrm{x}$ & $\mathrm{x}$ & $\mathrm{x}$ \\
\hline Fears and compensatory strategies & 28 & \multicolumn{4}{|c|}{$\begin{array}{l}\text { Fear hypoglycemic coma/not waking up, maintain higher glucose levels, set alarms to check } \\
\text { glucose levels overnight }\end{array}$} \\
\hline Disrupted sleep & 24 & \multicolumn{4}{|c|}{$\begin{array}{l}\text { Multiple interruptions, delayed sleep onset, unable to return to sleep, nightmares, rebound } \\
\text { hyperglycemia }\end{array}$} \\
\hline Next-day fatigue & 16 & \multicolumn{4}{|c|}{ Exhaustion, bad moods, and impaired functioning } \\
\hline Sex life & 24 & $\mathrm{X}$ & $\mathrm{x}$ & & $\mathrm{X}$ \\
\hline $\begin{array}{l}\text { Postponed, interrupted, or discontinued sexual } \\
\text { activity }\end{array}$ & 23 & \multicolumn{4}{|c|}{ Interrupted/discontinued sex, limited ability to enjoy sex, worry about disappointing partner } \\
\hline Reduced spontaneity & 4 & \multicolumn{4}{|c|}{ Fear of/preoccupation with hypoglycemia during sex } \\
\hline Physical health & 14 & $\mathrm{x}$ & $\mathrm{x}$ & & \\
\hline Other aspects of health negatively affected & 14 & \multicolumn{4}{|c|}{ Weight gain/unable to lose weight, comorbidities exacerbated, pregnancy complications } \\
\hline Mental health & 35 & $x$ & $\mathrm{X}$ & & $\mathrm{x}$ \\
\hline Emotional difficulties & 11 & \multicolumn{4}{|c|}{$\begin{array}{l}\text { Negative emotional states, ashamed/angry with self for recurrences, disordered eating } \\
\text { behaviors exacerbated }\end{array}$} \\
\hline Persistent stress & 24 & \multicolumn{4}{|c|}{ Fear of/preoccupation with the risk of hypoglycemia, less carefree } \\
\hline
\end{tabular}

Extracts may be coded to more than one subtheme, thus $\mathrm{N}$ for themes may exceed the sum of subtheme $\mathrm{N}$. Emotional impacts=effects on mood. Behavioral impacts=effects on actions or conduct. Cognitive impacts=effects on thinking or decision-making. Social impacts=effects on interactions with others.

QoL, quality of life.

of flexibility in making plans, with outings needing to be well-organized rather than spontaneous to mitigate risk. By contrast, some explained that they felt able to manage the risk of hypoglycemia because they were well-supported by family and friends.

\section{Work and studies}

\section{Reduced productivity and performance}

Participants experienced reduced productivity or performance at work or school/university due to hypoglycemia. They described exhaustion and concentration difficulties due to both nocturnal episodes and episodes that occurred during work hours. Difficulties with focus, alertness, and 'mental sharpness'were linked to suboptimal execution of tasks ('overlooking things', 'making mistakes', or 'missing deadlines'). They often interrupted tasks to manage hypoglycemia, which was annoying for them. They checked their glucose and treated hypoglycemia in secret to avoid unwanted attention or negative evaluation from colleagues. Participants described long recovery periods and felt pressured to resume tasks despite feeling unwell. They sometimes arrived late to work or took sick leave following nocturnal hypoglycemia.

\section{Fears and compensatory strategies}

Participants feared hypoglycemia at work and were worried about appearing unprofessional, frightening others, or embarrassing themselves. They maintained 
Box 1 Participant descriptions of the impact of

hypoglycemia on QoL domains

\section{Relationships and social life}

"My children have had to treat my hypos. Young children have had to see me shake uncontrollably and be very weak until I recover." (Woman) "You do not want to end up as a burden to others if you go and lose control, which dulls the desire to interact with others and be participatory/selfforgetting." (Man)

\section{Work and studies}

"Hypoglycaemia reduces my attention and ability to think clearly, so mistakes can happen. This can be very uncomfortable, especially in contact with customers." (Man)

"I get so nervous about getting low that I check very often at work. I fear what my employer thinks and whether they see me in a worse position than my colleagues." (Woman)

\section{Leisure and physical activity}

"It is annoying when sport has to be interrupted all the time and you cannot, like healthy people, just do what you want for as long as you want." (Man) "I can do craft hobbies and reading because they are low intensity and don't cause hypos. I would like to be brave one day and try new hobbies if I can get over my fears." (Woman)

\section{Everyday life}

"Driving long distances without a hypo is almost impossible. To be late for an appointment because of a hypo is simply uncomfortable." (Woman)

"To do something spontaneously at short notice is impossible, because I have to prepare all scenarios and drag luggage along with me." (Man) "I often make choices about what I eat based on my values. With hypos, I eat things that I don't want. Then the sword of Damocles hangs over my head because I know that it will result in a hypo or hyper." (Woman)

\section{Sleep}

"I run high at night because I'm afraid I will have a hypo in my sleep and not wake up." (Woman)

"The next day, I am useless. I am constantly behind the facts and feel lethargic and empty." (Man)

\section{Mental health}

"When I have low blood sugar, I am incredibly hard on myself and spend a lot of energy scolding myself!" (Woman)

"The stress associated with anticipating hypos is debilitating. I often get worked up about this and I feel really anxious/frustrated that my life is dictated by my blood sugar." (Woman)

\section{Sex life}

"Hypoglycemia destroys the ability to have sex and the sexual activity itself can induce hypoglycemia. There are few situations that are more despairing and at times humiliating. You are reminded that your body is a machine that has lost the ability to maintain itself and that you are the controller who at this very unfortunate time has lost control." (Man)

\section{Physical health}

"I'm afraid of comorbidities. Will I do everything I want? Can I become a mother and what type? What can I offer those around me? Why can't I have the job I have dreamed of all my life? I have such thoughts every time I have low blood sugar." (Woman)

higher glucose levels and checked their glucose frequently to prevent hypoglycemia. Some commented on the advantages of CGM for discreet glucose checking and hypoglycemia prevention at work.

\section{Limited employment prospects}

Some participants were self-employed, unemployed, retired, or felt limited in pursuing their 'dream job'. Some explained that it was difficult to get or maintain a job due to the risk of hypoglycemia. Others opted for part-time work for fewer hours and 'less work pressure'.

\section{Leisure and physical activity}

\section{Interrupted, discontinued, or canceled activities}

Participants 'cut short' or 'called off' sports, exercise, and leisure activities due to hypoglycemia. Some felt unable to work out as frequently as they wanted. Fatigue and concentration difficulties further contributed to reduced performance. They noted that hypoglycemia often restricted them and 'takes the fun out things', which was frustrating for them. Participants explained that the need to consume additional calories to manage (the risk of) hypoglycemia 'makes exercise seem pointless'.

\section{Fears and limited spontaneity}

Participants feared hypoglycemia during physical activity and stated that 'activities are difficult to implement spontaneously'. Rigorous planning was required to account for glucose fluctuations that occurred with exercise. Some attempted to prevent hypoglycemia by maintaining higher glucose levels and checking their glucose frequently, which could be disruptive and 'defeat the purpose' of the activity (eg, walking for relaxation). Some chose low-key or less physically active pursuits to prevent hypoglycemia. Others participated less often in certain activities (eg, leading church events) due to fear of hypoglycemia.

\section{Everyday life}

\section{Limited driving freedom}

Participants experienced driving as stressful due to fear of hypoglycemia while driving. They attempted to offset their fears by checking their glucose frequently and maintaining higher glucose levels while driving. Trips were delayed or interrupted due to hypoglycemia, which was annoying for them and meant that they had to cancel or arrive late to appointments. Some had been involved in a car accident due to hypoglycemia or had experienced discrimination when renewing their driver's license. Some mentioned that CGM had offered greater safety, security, and flexibility with driving.

\section{Day-to-day burdens}

Participants described the burden of constantly carrying hypoglycemia treatments and equipment. They felt frustrated when household duties had to be interrupted, postponed, or discontinued due to hypoglycemia. Participants were burdened by the financial costs associated with hypoglycemia, including treatments and diabetes supports not covered by insurance (eg, service dog).

\section{Limited dietary freedom}

Participants often had to ingest carbohydrates to treat hypoglycemia despite not being hungry, which conflicted with their healthy eating/weight loss goals and enjoyment 
of shared meals. Food choices were often dictated by glucose levels and some previously enjoyed foods had become too closely associated with hypoglycemia treatment. Some limited their alcohol intake due to fear of hypoglycemia and 'losing control'.

\section{Sleep}

Fears and compensatory strategies

Participants were afraid of hypoglycemic coma or not waking up from sleep due to hypoglycemia. Many attempted to prevent hypoglycemia by maintaining higher glucose levels overnight and setting alarms to check their glucose throughout the night. Participants felt tense when falling asleep due to the risk of hypoglycemia. Many commented on the benefits of CGM for alleviating fear and alerting them to low glucose. Some mentioned that CGM alarms "didn't always wake them $u p$ " or were too disruptive, which led some to switch off alarms.

\section{Disrupted sleep}

Participants and their spouses/partners experienced multiple sleep interruptions due to hypoglycemia, including sensor alarms, delayed sleep onset due to glucose fluctuations, difficulties falling asleep after waking up with hypoglycemia, nightmares, and rebound hyperglycemia due to overtreatment of hypoglycemia and associated counterregulation.

\section{Next-day fatigue}

Participants felt unrested and 'drained' following nocturnal hypoglycemia and sleep disruptions. Next-day fatigue was associated with 'bad moods' and impaired functioning. Some mentioned headaches and feeling hungover, which was associated with concentration difficulties and 'possible incapacity for work'.

\section{Sex life}

Sexual activities were often postponed, interrupted, or discontinued due to hypoglycemia. Some participants were 'too tired' or 'not receptive' to sexual advances following hypoglycemia. Others were unable to achieve climax and some men reported difficulties getting an erection. Consequently, 'lust or pleasure dissipated'and they felt 'bad', 'frustrated', 'embarrassed', 'insecure', or 'humiliated'. Participants were worried about disappointing or frightening their partner, particularly in a new relationship and/or when their partner was unfamiliar with hypoglycemia. Since sex often induced hypoglycemia, participants lacked spontaneity with sex or were preoccupied with fear of hypoglycemia during sex.

\section{Physical health}

Due to consuming additional calories to treat hypoglycemia, some had gained weight or found it difficult to lose weight, and felt uncomfortable with their body. Some women explained that, prior to pregnancy, it was difficult to achieve recommended hemoglobin A1c levels because they were too scared to maintain glucose levels in such a low range or overtreated hypoglycemia and experienced rebound hyperglycemia. Some mentioned that comorbidities (eg, multiple sclerosis) were exacerbated by hypoglycemia. Participants explained that they were fearful of long-term health complications due to frequent hypoglycemia and/or rebound hyperglycemia.

\section{Mental health}

\section{Emotional difficulties during and after episodes}

Participants described many emotional states during and after hypoglycemia, including irritability, sadness, helplessness, and general moodiness. They felt ashamed or angry with themselves for recurrences. Some explained that hypoglycemia exacerbated stress and pre-existing disordered eating behaviors, whereby they suspended or turned off their insulin pumps and/or skipped meals to compensate for calories consumed for hypoglycemia treatment.

\section{Persistent emotional impacts of hypoglycemia}

Participants described a pervasive sense of anxiety and 'tenseness' related to the ever-present threat of hypoglycemia. They reported an enduring fear of hypoglycemia between episodes. Many were preoccupied with hypoglycemia and always 'working on' hypoglycemia, at the expense of enjoying leisure activities and quality time with others. Participants commented that they no longer had "peace of mind': "Never again will I be carefree".

\section{DISCUSSION}

This web-based qualitative study is the first to explore the impact of hypoglycemia on areas of life that adults with type 1 diabetes identify as important to their overall QoL. The findings show that hypoglycemia affects many areas of life important to adults with type 1 diabetes, including their relationships and social life, work and studies, leisure and physical activity, everyday life, sleep, sex life, physical health, and mental health. Participants described the short-term impacts of hypoglycemic episodes as well as the persistent impacts of living with the risk of hypoglycemia. Common reports across domains relating to hypoglycemic episodes were interruptions, limited participation in activities, reduced performance, exhaustion, and concentration difficulties. Common reports relating to living with the risk of hypoglycemia were fear of and preoccupation with hypoglycemia, maintenance of higher glucose and frequent glucose checking to prevent hypoglycemia, and limited spontaneity. These findings were largely consistent across four European countries.

Participants experienced emotional, behavioral, cognitive, and social impacts in most QoL domains, which indicates that hypoglycemia affects many areas of functioning, including the way individuals think, feel, behave, and interact with others. In addition to reported impacts on mental health, participants indicated that hypoglycemia affected their emotional functioning in all other QoL domains, which shows that hypoglycemia can have a 
pervasive impact on emotional well-being. Fear of hypoglycemia was mentioned frequently across domains, with some participants describing long-standing fears of dying during sleep.

Past research has examined the impact of diabetes on sex life ${ }^{20}$ and fear of hypoglycemia during sex for young adults with diabetes, ${ }^{21}$ but not the impact of hypoglycemia on sex life for adults with type 1 diabetes. Participants in this study felt less able to derive enjoyment and pleasure from sex due to (the risk of) hypoglycemia, and consequently, felt frustrated, embarrassed, insecure, and humiliated. When considered alongside other findings that hypoglycemia limits participation in and enjoyment of social interactions, this finding implies that hypoglycemia hinders an individual's ability to relate to others in many ways.

Generic QoL measures typically assess other domains of QoL that were rarely mentioned by participants in the current study, including financial and spiritual factors, ${ }^{22}$ although participants were not prompted to consider all QoL domains. With respect to financial impacts, the countries targeted in this study have universal healthcare systems, thus the impact of hypoglycemia on financial resources may be inherently lessened. There could be a greater impact of hypoglycemia on QoL in countries without universal healthcare systems.

The finding that positive support from others helps individuals to cope with the challenges of hypoglycemia indicates that the burden of hypoglycemia can be mitigated if support needs are met. While participants mentioned the benefits of diabetes technologies for hypoglycemia prevention, there were conflicting reports about the advantages of technologies for sleep, whereby CGM sensors allayed fears of nocturnal hypoglycemia but disrupted sleep with alarms. The finding that some participants switch off their CGM alarms indicates that alarms are burdensome despite keeping participants safe.

\section{Strengths and limitations}

The 'Wheel of Life' was a key strength of this study as it provided a novel method for exploring areas of life that participants defined as important to their QoL, without researchers imposing a definition. While some participants reported minimal to no impact on certain domains, there was no mention of positive impacts of hypoglycemia, unlike previous studies in which people with diabetes have reported the benefits of diabetes management for healthy eating and exercise. ${ }^{20}{ }^{23}$ However, the 'Wheel of Life' instructions prompted participants to consider the various impacts of hypoglycemia and included examples of challenges, so participants may have been more primed to consider negative impacts. Nonetheless, participants could openly describe any type of impact relevant to their experience. The web-based format offered participants the time to consider their responses carefully and allowed for lengthy and candid descriptions of sensitive issues (eg, sexuality). Conversely, researchers were unable to seek clarification of meaning, and some meaning may have been lost during translation.

While the web-based format enabled access to participants from multiple countries, this study may be subject to self-selection bias. There was an over-representation of participants with IAH, which may have further skewed responses toward reports of negative impacts. There was little mention of hypoglycemia awareness in qualitative responses, which may indicate that participants were not concerned about reduced awareness. While participants mentioned the impact of hypoglycemia on others (eg, CGM alarms being disruptive), it may be that they underestimate the impact of hypoglycemia on their relatives ${ }^{2}$ and the findings likely do not capture the full impact of hypoglycemia on relatives. The majority reported no severe episodes in the past year, which may imply that the impacts described do not refer solely to severe episodes and/or that severe episodes can have a long-standing impact. Future studies could differentiate between impacts of hypoglycemic episodes requiring the assistance of others versus episodes that are self-treated.

There was an over-representation of women in this sample, although quantitative analysis revealed minimal differences and free-text responses were not observed to be qualitatively different (eg, box 1). Further research is needed to examine the impact of hypoglycemia on QoL among men with type 1 diabetes, especially since there is evidence of gender differences in fear of hypoglycemia. ${ }^{24}$ This study may have been biased in terms of greater representation of socially advantaged people with internet access and social media engagement. Nonetheless, data were collected from a large, heterogeneous, multi-country (though mostly European) sample.

\section{CONCLUSIONS}

This study emphasizes the profound impact of hypoglycemia on areas of life that typically serve as an individual's resources, including their relationships and vocational activities. The findings indicate that hypoglycemia can interfere with basic human needs being met, from the physiological need for sleep to the social need for connection with others, which may account for the relationship between (fear of) hypoglycemia and mental health comorbidities. ${ }^{25}$ The 'Wheel of Life' was instrumental in eliciting rich personal accounts and should be used in future studies to determine whether these findings are corroborated in unselected and culturally diverse samples.

Despite the rise in tools to defend against hypoglycemia, ${ }^{26}{ }^{27}$ adults with type 1 diabetes continue to report difficulties with hypoglycemia management. Maintaining higher glucose levels to prevent hypoglycemia is common ${ }^{58-30}$ and can have serious health implications. ${ }^{31}$ The findings indicate that, beyond hypoglycemic episodes, fear of hypoglycemia and compensatory strategies to prevent hypoglycemia can be disruptive and debilitating in themselves. Thus, the absence of severe 
hypoglycemia may not always reflect minimal impact on QoL. The findings can inform healthcare professionals' understanding of the multifaceted impact of hypoglycemia on psychosocial functioning and diabetes selfcare behaviors. Diabetes services should be aware of and address the burden of hypoglycemia to provide personcentered care. Clinicians could ask individuals how hypoglycemia affects important areas of their lives to better understand the personal impact, then facilitate access to tools and develop tailored hypoglycemia management plans accordingly.

\section{Author affiliations}

1Department of Psychology, University of Southern Denmark, Odense, Denmark ${ }^{2}$ The Australian Centre for Behavioural Research in Diabetes, Diabetes Victoria, Melbourne, Victoria, Australia

${ }^{3}$ School of Psychology, Deakin University, Melbourne, Victoria, Australia ${ }^{4}$ School of Health and Related Research, University of Sheffield, Sheffield, UK ${ }^{5}$ Department of Oncology and Metabolism, University of Sheffield, Sheffield, UK ${ }^{6}$ Department of Diabetes, King's College London, London, UK

${ }^{7}$ Department of Internal Medicine, Radboud University Medical Center, Nijmegen, The Netherlands

${ }^{8}$ Department of Internal Medicine, Maastricht University Medical Centre, Maastricht, The Netherlands

${ }^{9}$ Research Institute Diabetes Academy Mergentheim (FIDAM), Bad Mergentheim, Germany

${ }^{10}$ Research Unit, Steno Diabetes Center Odense, Odense, Denmark

Acknowledgements The authors thank the adults with type 1 diabetes who participated in this study. They acknowledge Manon Coolen and Kevin Matlock (University of Southern Denmark), who contributed to development of the study concept, design and protocol. They further acknowledge Uffe Søholm, Nanna Lindekilde and Manon Coolen (University of Southern Denmark), who translated survey materials.

Contributors HC, MB, MVJ, CH, JS and FP developed the study concept and design, including use of the 'Wheel of Life' activity previously developed by JS. $\mathrm{HC}, \mathrm{MB}, \mathrm{MVJ}, \mathrm{CH}, \mathrm{JC}, \mathrm{SH}, \mathrm{SA}, \mathrm{BdG}, \mathrm{NH}, \mathrm{JS}$ and FP contributed to development of the study protocol. HC, MB, MVJ, SH, BdG, NH and KF-G completed and managed ethics applications in target countries. MVJ, CH, NH, KF-G and FP conducted nonEnglish transactions of survey materials. HC, MB, MVJ, JC, SH, BdG, NH, KF-G, JS and FP assisted with participant recruitment. $\mathrm{HC}$ and MVJ coded data. $\mathrm{HC}$ wrote the manuscript. All authors edited the manuscript for critical content and approved the final version.

Funding This project has received funding from the Innovative Medicines Initiative 2 Joint Undertaking (JU) under grant agreement no. 777460. The JU receives support from the European Union's Horizon 2020 research and innovation programme and EFPIA and T1D Exchange, JDRF, International Diabetes Federation (IDF), The Leona M. and Harry B. Helmsley Charitable Trust. CH and JS are supported by core funding to the Australian Centre for Behavioural Research in Diabetes provided by the collaboration between Diabetes Victoria and Deakin University.

\section{Competing interests None declared.}

Patient consent for publication Not required.

Ethics approval Ethics approval was granted by the University of Southern Denmark Research Ethics Committee (\#19/78420), German Society for Psychology Research Ethics Committee (\#HermannsNorbert2020-05-12VA), Radboud University Medical Centre Research Ethics Committee (2020-6587), and UK Health and Social Care Research Ethics Committee (20-NI-0054).

Provenance and peer review Not commissioned; externally peer reviewed.

Data availability statement Data are available on reasonable request via contact with the corresponding author (https://orcid.org/0000-0001-8328-0869), provided that data are to be used for research projects related to health sciences. Data are deidentified participant data from a web-based qualitative survey.

Supplemental material This content has been supplied by the author(s). It has not been vetted by BMJ Publishing Group Limited (BMJ) and may not have been peer-reviewed. Any opinions or recommendations discussed are solely those of the author(s) and are not endorsed by BMJ. BMJ disclaims all liability and responsibility arising from any reliance placed on the content. Where the content includes any translated material, BMJ does not warrant the accuracy and reliability of the translations (including but not limited to local regulations, clinical guidelines, terminology, drug names and drug dosages), and is not responsible for any error and/or omissions arising from translation and adaptation or otherwise.

Open access This is an open access article distributed in accordance with the Creative Commons Attribution Non Commercial (CC BY-NC 4.0) license, which permits others to distribute, remix, adapt, build upon this work non-commercially, and license their derivative works on different terms, provided the original work is properly cited, appropriate credit is given, any changes made indicated, and the use is non-commercial. See: http://creativecommons.org/licenses/by-nc/4.0/.

\section{ORCID iDs}

Hannah Chatwin http://orcid.org/0000-0001-7248-8568

Melanie Broadley http://orcid.org/0000-0003-4408-6304

Mette Valdersdorf Jensen http://orcid.org/0000-0003-0605-3317

Christel Hendrieckx http://orcid.org/0000-0002-0075-828X

Jill Carlton http://orcid.org/0000-0002-9373-7663

Simon Heller http://orcid.org/0000-0002-2425-9565

Stephanie Amiel http://orcid.org/0000-0003-2686-5531

Bastiaan de Galan http://orcid.org/0000-0002-1255-7741

Norbert Hermanns http://orcid.org/0000-0002-2903-2677

Katharina Finke-Groene http://orcid.org/0000-0002-3927-6501

Jane Speight http://orcid.org/0000-0002-1204-6896

Frans Pouwer http://orcid.org/0000-0002-8172-9818

\section{REFERENCES}

1 Bolinder J, Antuna R, Geelhoed-Duijvestijn P, et al. Novel glucosesensing technology and hypoglycaemia in type 1 diabetes: a multicentre, non-masked, randomised controlled trial. Lancet 2016;388:2254-63.

2 Rankin D, Elliott J, Heller S, et al. Experiences of hypoglycaemia unawareness amongst people with type 1 diabetes: a qualitative investigation. Chronic IIIn 2014;10:180-91.

3 Yeh JS, Sung S-H, Huang H-M, et al. Hypoglycemia and risk of vascular events and mortality: a systematic review and metaanalysis. Acta Diabetol 2016:53:377-92.

4 Brod M, Christensen T, Bushnell DM. Impact of nocturnal hypoglycemic events on diabetes management, sleep quality, and next-day function: results from a four-country survey. $J$ Med Econ 2012;15:77-86.

5 Dømgaard M, Bagger M, Rhee NA, et al. Individual and societal consequences of hypoglycemia: a cross-sectional survey. Postgrad Med 2015;127:438-45.

6 American Diabetes Association. 5. Lifestyle management: standards of medical care in diabetes-2019. Diabetes Care 2019;42:S46-60.

7 Speight J, Holmes-Truscott E, Hendrieckx C, et al. Assessing the impact of diabetes on quality of life: what have the past 25 years taught us? Diabet Med 2020;37:483-92.

8 Chatwin $\mathrm{H}$, Broadley M, Speight $\mathrm{J}$, et al. The impact of hypoglycaemia on quality of life outcomes among adults with type 1 diabetes: a systematic review. Diabetes Res Clin Pract 2021;174:108752.

9 Speight J, Reaney MD, Barnard KD. Not all roads lead to Rome-a review of quality of life measurement in adults with diabetes. Diabet Med 2009;26:315-27.

10 Martyn-Nemeth P, Duffecy J, Fritschi C, et al. Challenges imposed by hypoglycemia in adults with type 1 diabetes. Clin Nurs Res 2019;28:947-67.

11 Litterbach E, Holmes-Truscott E, Pouwer F, et al. 'I wish my health professionals understood that it's not just all about your $\mathrm{HbA}_{1}$ !'. Qualitative responses from the second Diabetes MILES - Australia (MILES-2) study. Diabet Med 2020;37:971-81.

12 Speight J, Woodcock A, Reaney M, et al. Expectations and experiences of transplant: a qualitative study of people with type 1 diabetes undergoing pancreatic islet transplantation. AIDPIT Study Group: 29th Workshop of the Artificial Insulin Delivery Pancreatic and Islet Transplantation (AIDPIT) Study Group 2010.

13 Speight J, Woodcock A. The wheel of life: a novel method for exploring health-related quality of life (HRQoL). Quality of Life Research 2010;19:1-144.

14 Speight J, Barendse SM, Singh $\mathrm{H}$, et al. Characterizing problematic hypoglycaemia: iterative design and preliminary psychometric 
validation of the hypoglycaemia awareness questionnaire (HypoA-Q). Diabet Med 2016;33:376-85.

15 Gold AE, MacLeod KM, Frier BM. Frequency of severe hypoglycemia in patients with type I diabetes with impaired awareness of hypoglycemia. Diabetes Care 1994;17:697-703.

16 Grabman J, Vajda Bailey K, Schmidt K, et al. An empirically derived short form of the Hypoglycaemia Fear Survey II. Diabet Med 2017;34:500-4.

17 Peyrot M, Burns KK, Davies M, et al. Diabetes Attitudes Wishes and Needs 2 (DAWN2): a multinational, multi-stakeholder study of psychosocial issues in diabetes and person-centred diabetes care. Diabetes Res Clin Pract 2013;99:174-84.

18 Wild D, Grove A, Martin M, et al. Principles of good practice for the translation and cultural adaptation process for patient-reported outcomes (PRO) measures: report of the ISPOR task force for translation and cultural adaptation. Value Health 2005;8:94-104.

19 Harris PA, Taylor R, Thielke R, et al. Research electronic data capture (REDCap)-a metadata-driven methodology and workflow process for providing translational research informatics support. J Biomed Inform 2009;42:377-81.

20 Bradley C, Todd C, Gorton T, et al. The development of an individualized questionnaire measure of perceived impact of diabetes on quality of life: the ADDQoL. Qual Life Res 1999;8:79-91.

21 Pinhas-Hamiel O, Tisch E, Levek N, et al. Sexual lifestyle among young adults with type 1 diabetes. Diabetes Metab Res Rev 2017;33:e2837.

22 Group W. The world Health organization quality of life assessment (WHOQOL): position paper from the world Health organization. Soc Sci Med 1995;41:1403-9.

23 Stuckey HL, Mullan-Jensen C, Kalra S, et al. Living with an adult who has diabetes: qualitative insights from the second Diabetes
Attitudes, Wishes and Needs (DAWN2) study. Diabetes Res Clin Pract 2016:116:270-8.

24 Gjerløw E, Bjørgaas MR, Nielsen EW, et al. Fear of hypoglycemia in women and men with type 1 diabetes. Nurs Res 2014;63:143-9.

25 Anderbro T, Gonder-Frederick L, Bolinder J, et al. Fear of hypoglycemia: relationship to hypoglycemic risk and psychological factors. Acta Diabetol 2015;52:581-9.

26 Vallis M, Jones A, Pouwer F. Managing hypoglycemia in diabetes may be more fear management than glucose management: a practical guide for diabetes care providers. Curr Diabetes Rev 2014;10:364-70.

27 Choudhary P, Rickels MR, Senior PA, et al. Evidence-Informed clinical practice recommendations for treatment of type 1 diabetes complicated by problematic hypoglycemia. Diabetes Care 2015;38:1016-29.

28 Due-Christensen M, Willaing I, Ismail K, et al. Learning about type 1 diabetes and learning to live with it when diagnosed in adulthood: two distinct but inter-related psychological processes of adaptation a qualitative longitudinal study. Diabet Med 2019;36:742-52.

29 Speight J, Barendse SM, Singh H, et al. Cognitive, behavioural and psychological barriers to the prevention of severe hypoglycaemia: a qualitative study of adults with type 1 diabetes. SAGE Open Med 2014;2:205031211452744.

30 Diago-Cabezudo JI, Madec-Hily A, Aslam A. Perceptions of hypoglycemia and self-monitoring of blood glucose in insulin-treated diabetes patients: results from a European online survey. Diabetes Management 2013;3:15-23.

31 Diabetes Control and Complications Trial Research Group, Nathan DM, Genuth S, et al. The effect of intensive treatment of diabetes on the development and progression of long-term complications in insulin-dependent diabetes mellitus. N Engl J Med 1993;329:977-86. 